\title{
Dynamic economic emission dispatch using ant lion optimization
}

\author{
Hardiansyah Hardiansyah \\ Department of Electrical Engineering, Tanjungpura University, Indonesia
}

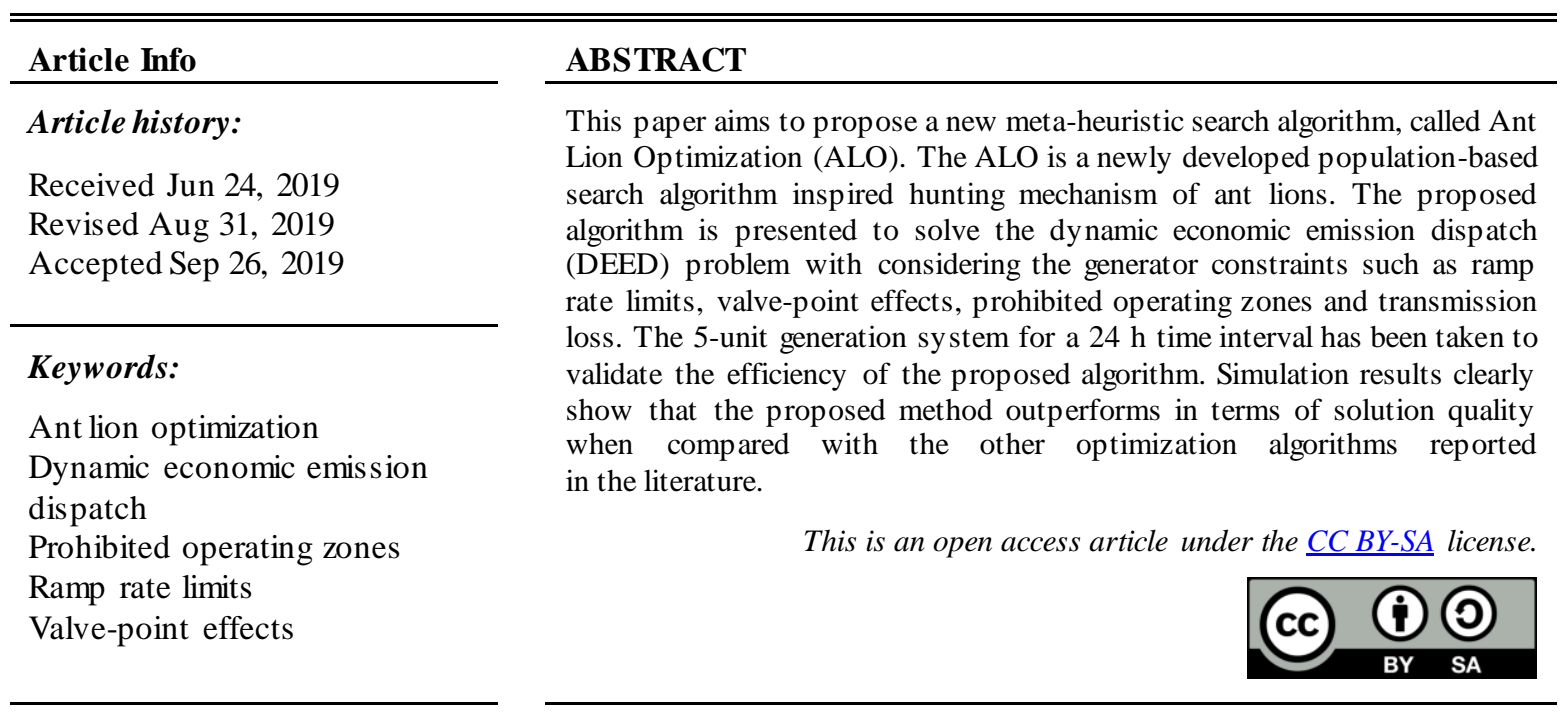

Corresponding Author:

Hardiansyah Hardiansyah,

Department of Electrical Engineering,

Tanjungpura University,

Jln. Ahmad Yani, Pontianak 78124, Indonesia.

Email: hardi_eka@yahoo.com

\section{INTRODUCTION}

The Dynamic Economic Dispatch (DED) formulation allows for a more advanced treatment of the Economic Dispatch (ED) problem. The additional of certain periods of time in which the traditional economic dispatch is scheduled and operated, and the variation of the load demands over this period of time, have made the DED a more realistic representation of real conditions. The fundamental goal of dynamic economic dispatch problem of electric power generation is to schedule the committed generating unit outputs in order to meet the predicted load demand with minimum operating cost, while satisfying all system equality and inequality constraints. Therefore, the DED problem is a very restricted large-scale nonlinear optimization problem [1,2]. The presence of the valve-point effect results ripples in the heat-rate curves so that the objective function becomes non-convex, discontinuous, and with multiple minima [3-6]. The fuel cost function with valve-point effects in the generating units is the accurate model of the DED problem [7-9].

Currently strategically utilizing available resources and achieving electricity at bargain prices without sacrificing social benefits is of utmost importance. The environmental pollution plays a major role as it had a major threat on the human society. Hence, it became compulsory to deliver electricity at a minimum cost as well as to maintain minimum level of emissions. The lowest emissions are considered as one of the goals in combined economic and emission dispatch problems, along with economic costs. Atmospheric pollution due to release of gases such as nitrogen oxides $(\mathrm{NO})$, carbon dioxide $\left(\mathrm{CO}_{2}\right)$, and sulphur oxides $\left(\mathrm{SO}_{\mathrm{X}}\right.$ ) into atmosphere by fossil-fuel based thermal power plant affects not only humans but also other forms of life such as birds, animals, plants and fish, while causes global warming too [10-14].

The emission dispatch is a short-term alternative that should be optimized, besides fuel cost goals. Thus, DEED problem can be handled as a multi-objective optimization problem and requires only small 
modification to include emission. Therefore, the DEED problem can be converted into a single objective problem by linear combination of various objectives using different weights. The important characteristic of the weighted sum method is that different pareto-optimal solutions can be obtained by varying the weights [15]. The static economic dispatch problem with considering valve-point effects and prohibited operating zones have been solved in [16-18]. A number of reported works has considered the prohibited operating zones in DED problem [19-22], however, the emission has not considered in these papers.

Recently, a novel nature inspired algorithm, called Ant Lion Optimization (ALO) [23], has been developed by Mirjalili. In this paper, the ALO algorithm has been used to solve the DEED problem considering ramp rate limits, valve-point effects, prohibited operating zones, and transmission loss. The effectiveness of the proposed method has been demonstrated on 5-unit generation system and than compared with other optimization results reported in literature.

\section{PROBLEM FORMULATION}

The purpose of DEED problem is to find the optimal schedule of output powers of online generating units with predicted power demands over a certain period of time to meet the power demand at minimum both operating cost and emission simultaneously.

The objective function of the DEED problem can be formulated as follow:

$$
\begin{gathered}
F_{T}=w_{1} * \sum_{t=1}^{T} \sum_{i=1}^{N} F_{i, t}\left(P_{i, t}\right)+w_{2} * h * \sum_{t=1}^{T} \sum_{i=1}^{N} E_{i, t}\left(P_{i, t}\right) \\
\text { for } i=1,2, \cdots, N ; t=1,2, \ldots, T
\end{gathered}
$$

where $F_{T}$ is the total operating cost over the whole dispatch period, $T$ is the number of hours in the time horizon, $N$ is the total number of generating units, $w_{1}$ is weighting factor for economic objective such that its value should be within the range 0 and 1 , and $w_{2}$ is the weighting factor for emission objective which is given by $w_{2}=\left(1-w_{1}\right)$, and $h_{i}$ is the price penalty factor. $F_{i, t}\left(P_{i, t}\right)$ and $E_{i, t}\left(P_{i, t}\right)$ are the generation cost and the amount of emission for unit $i$ at time interval $t$, and $P_{i, t}$ is the real power output of $i$ th generating unit at time period $t$.

The production cost of generating unit considering valve-point effect is defined as:

$$
F_{i, t}\left(P_{i, t}\right)=\left(\begin{array}{l}
a_{i} P_{i, t}^{2}+b_{i} P_{i, t}+c_{i}+ \\
\left|e_{i} \times \sin \left(f_{i} \times\left(P_{i, \min }-P_{i, t}\right)\right)\right|
\end{array}\right)
$$

where the constant $a_{i}, b_{i}$, and $c_{i}$ represents generator cost coefficients and $e_{i}$ and $f_{i}$ represents valve-point effect coefficients of the $i$ th generating unit.

Utilization of thermal power plant consuming fossil fuel is with release of high amounts of $\mathrm{NO}_{\mathrm{X}}$, they are strongly requested by the environmental protection agency to reduce their emissions. The NOx emission of the thermal power station having $N$ generating units at interval $t$ in the scheduling horizon is represented by the sum of quadratic and exponential functions of power generation of each unit. The emission due to $i$ th thermal generating unit can be expressed as:

$$
E_{i, t}\left(P_{i, t}\right)=\left(\alpha_{i} P_{i, t}^{2}+\beta_{i} P_{i, t}+\gamma_{i}+\eta_{i} \exp \left(\delta_{i} P_{i, t}\right)\right)
$$

where $\alpha_{i}, \beta_{i}, \gamma_{i}, \eta_{i}$ and $\delta_{i}$ are emission coefficients of the $i$ th generating unit. The minimization of the fuel cost and emission are subjected to the following equality and inequality constraints.

\subsection{Power balance constraint}

The total generated real power should be the same as total load demand plus the total line loss.

$$
\sum_{i=1}^{N} P_{i, t}=P_{D, t}+P_{L, t}
$$

where $P_{D, t}$ and $P_{L, t}$ are the demand and transmission loss in $\mathrm{MW}$ at time interval $t$, respectively. The transmission loss $P_{L, t}$ can be expressed by using $B$ matrix technique and is defined by (5) as, 


$$
P_{L, t}=\sum_{i=1}^{N} \sum_{j=1}^{N} P_{i, t} B_{i j} P_{j, t}
$$

where $B_{i j}$ is the $i j$-th element of the loss coefficient square matrix of size $N$.

\subsection{Generation limits}

The real power output of each generators should lie between minimum and maximum limits.

$$
P_{i, \min } \leq P_{i, t} \leq P_{i, \max }
$$

\subsection{Ramp rate limits}

The ramp-up and ramp-down constraints can be written as (7) and (8), respectively.

$$
\begin{aligned}
& P_{i, t}-P_{i, t-1} \leq U R_{i} \\
& P_{i, t-1}-P_{i, t} \leq D R_{i}
\end{aligned}
$$

where $P_{i, t}$ and $P_{i, t-1}$ are the present and previous real power outputs, respectively. $U R_{i}$ and $D R_{i}$ are the ramp-up and ramp-down limits of $i$ th unit (in units of $\mathrm{MW} /$ time period). To consider the ramp rate limits and real power output limits constraint at the same times, therefore, generator capacity limit (6) can be rewritten as follows:

$$
\max \left\{P_{i, \min }, P_{i, t-1}-D R_{i}\right\} \leq P_{i, t} \leq \min \left\{P_{i, \max }, P_{i, t-1}+U R_{i}\right\}
$$

\subsection{Prohibited operating zones}

Generating units may have certain restricted operating zone due to limitations of machine components or instability concerns. The possible operating zones of the generator can be described as follows [7, 9]:

$$
P_{i, t} \in\left\{\begin{array}{l}
P_{i, \min } \leq P_{i, t} \leq P_{i, 1}^{l} \\
P_{i, k-1}^{u} \leq P_{i, t} \leq P_{i, k}^{l}, \quad k=2,3, \ldots, p z_{i} \\
P_{i, p z_{i}}^{u} \leq P_{i, t} \leq P_{i, \max }, i=1,2, \ldots, n_{p z}
\end{array}\right.
$$

where $P_{i, k}^{l}$ and $P_{i, k}^{u}$ are the lower and upperboundary of prohibited operating zone of $i$ th unit, respectively. Here, $p z_{i}$ is the number of prohibited zones of $i$ th unit and $n_{p z}$ is the number of units which have prohibited operating zones.

\section{ANT LION OPTIMIZATION}

Ant Lion Optimizer (ALO) is a novel nature-inspired algorithm proposed by Sayedali Mirjalili in 2015 [23]. The ALO algorithm emulates the hunting mechanism of antlions in nature. There are five main steps of the algorithm such that random walk of ants, building traps, entrapment of ants in traps, catching preys, and re-building traps. An antlion larvae digs a cone-shaped pit in sand by moving along a circular path and throwing out sands by using massive jaws. After digging the trap, the larvae hides underneath the botto $\mathrm{m}$ of the cone and waits for insect to be trapped in the pit. When a prey in caught, it will be pulled and consumed. After that, the antlions throw the leftovers outsode the pit and improve the pit for the next hunt.

\subsection{Random walk of ants}

The ALO algorithm imitates the interaction between ant lions and ants in the trap. For such interaction models, ants are required to move over the search space and antlions are allowed to hunt them and become fitter using traps. Since ants move stochastically in nature when searching for food, a random walk is chosen for the modeling ants'movement as follows:

$$
X(t)=\left[0, \operatorname{cums}\left(2 r\left(t_{1}\right)-1, \operatorname{cums}\left(2 r\left(t_{2}\right)-1, \ldots, \operatorname{cums}\left(2 r\left(t_{n}\right)-1\right]\right.\right.\right.
$$


where cums calculates the cumulative sum and $r(t)$ is defined as follows:

$$
r(t)=\left\{\begin{array}{l}
1, \text { if } \text { rand }>0.5 \\
0, \text { if rand } \leq 0.5
\end{array}\right\}
$$

The position of ants are stored and used during optimization process in the following matrix:

$$
M_{a n t}=\left[\begin{array}{lccc}
a n t_{1,1} & a n t_{1,2} & \ldots & a n t_{1, d} \\
a n t_{2,1} & a n t_{2,2} & \ldots & a n t_{2, d} \\
\vdots & \vdots & & \vdots \\
a n t_{n, 1} & a n t_{n, 2} & \ldots & a n t_{n, d}
\end{array}\right]
$$

where, $M_{a n t}$ is matrix to save the position of each ant, ant $t_{i j}$ is value of $j$ th variable (dimension) of $i$ th ant, $n$ is number of ants, and $d$ is number of variables. Random walk of ants are being normalized to keep them moving within the search space using the following equation:

$$
X_{i}^{t}=\frac{\left(X_{i}^{t}-a_{i}\right) \times\left(d_{i}-c_{i}^{t}\right)}{\left(d_{i}^{t}-a_{i}\right)}+c_{i}
$$

where $a_{i}$ indicates the minimum of random walk of $i$ th variable, $d_{i}$ is the maximum of random walk in $i$ th variable, $c_{i}^{t}$ is the minimum of $i$ th variable at $t$ th iteration, and $d_{i}^{t}$ indicates the maximum $i$ th variable at $t$ th iteration.

\subsection{Trapping in ant lion's pits}

The following equations are used to represent mathematically model of antlions pits.

$$
\begin{aligned}
& c_{i}^{t}=\text { Antlion }_{+}+c^{t} \\
& d_{i}^{t}=\text { Antlion }_{3}+d^{t}
\end{aligned}
$$

where $c^{t}$ is the minimum of all variables at $t$ th iteration, $d^{t}$ indicates the vector including the maximum of all variables at $t$ th iteration, $c_{i}^{t}$ is the minimum of all variables for $i$ th ant, $d_{i}^{t}$ is the maximum of all variables for $i$ th ant, and Antlion ${ }^{t}$ shows the position of the selected $j$ th antlion at $t$ th iteration.

\subsection{Building trap}

The ant lion's hunting ability is modelled by roulette wheel operator for selecting ant lions based on their fitness during iterations. This mechanism gives great probabilities to the fitter ant lions for catching preys.

\subsection{Sliding ants towards ant lion}

Ant lions be able to build traps proportional to their fitness and ants are necessary to move randomly. Once the ant is in the trap, ant lions will shoot sands outwards the center of the pit. This behavior slides down the trapped ant in the trap. The radius of ant's random walk is reduced and it can be written as follows:

$$
\begin{aligned}
& c^{t}=\frac{c^{t}}{I} \\
& d^{t}=\frac{d^{t}}{I}
\end{aligned}
$$


where $I$ is a ratio, $c^{t}$ is the minimum of all variables at $t$ th iteration, $d^{t}$ indicates the vector including the maximu $m$ of all variables at $t$ th iteration.

\subsection{Catching prey and re-building the pit}

The final stage of hunt is when ant reaches the bottom of the pit and being trapped in the ant lion's jaw. The ant lion attracts the ant inside the sand and consumes its body. To mimic this process, it is assumed that capture of prey occurs when ants become fitter (entry into the sand) rather than the corresponding ant lion. Ant lion is required to modernize its location to the latest position of the hunted ant to improve its chance of catching new prey. It is represented by the following equation:

$$
\text { Antlion }=A n t_{i}^{t} \text {, if } f\left(\text { Ant }_{i}^{t}\right)>f(\text { Antlion })
$$

where $t$ shows the current iteration, Antlion shows the position of selected $j$ th antlion at $t$ th iteration, and $A n t_{i}^{t}$ indicates the position of $i$ th ant at $t$ th iteration.

\subsection{Elitism}

The best ant lion finished so far is maintained as the elite. Since the elite is the best ant lion, it should be able to affect the movements of all ants during iterations. It is assumed that every random walks of ants around a chosen ant lion by the roulette wheel and the elite instantaneously as follows:

$$
A n t_{i}^{t}=\frac{R_{A}^{t}+R_{E}^{t}}{2}
$$

where $R_{A}^{t}$ is the random walk around the antlion selected by the roulette wheel at $t$ th iteration, $R_{E}^{t}$ is the random walk around the elite at $t$ th iteration, and $A n t_{i}^{t}$ indicates the position of $i$ th ant at $t$ th iteration. Hence, the pseudo code of the ALO algorithm is shown in Table 1.

Table 1. Pseudo-code of ALO

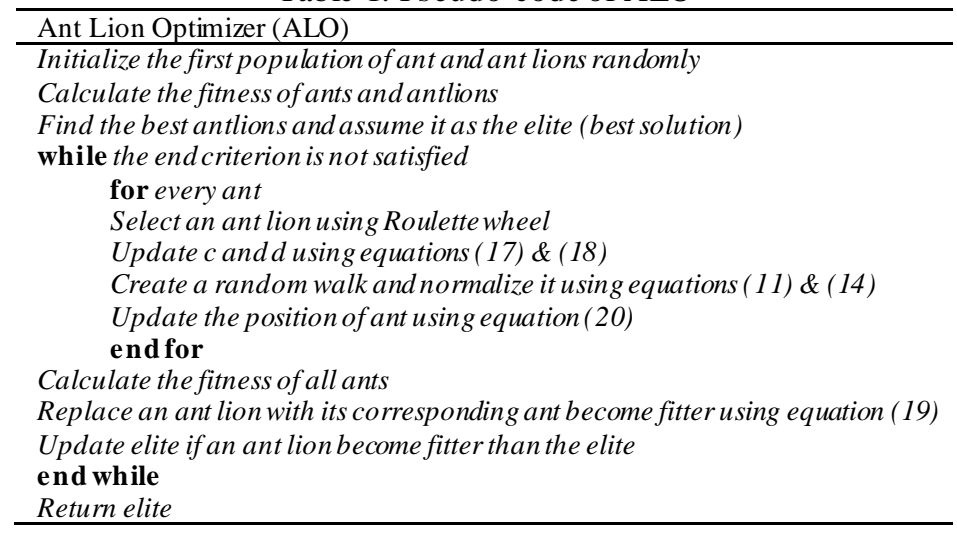

\section{RESULTS AND DISCUSSION}

In order to demonstrate the effectiveness of the proposed approach, a 5-unit generation system with non-smooth fuel cost and emission functions are used. The fuel cost coefficients including valve-point effects, emission coefficients, generation limits, ramp rate limits, prohibited operating zones, B-loss coefficients, and load demand in each interval are given in Appendix, which is taken from [24]. The demand of the system has been divided into 24 intervals. The transmission losses are calculated using B-loss coefficients formula. The parameters of algorithm used for simulation are: max generation $=100$; population size $=40$.

The best solutions of the dynamic economic dispatch (DED), dynamic economic emission dispatch (DEED) and pure dynamic emission dispatch (PDED) are given in Tables 2, 3 and 4, respectively. Table 2 shows hourly generation schedule, cost and emission obtained from DED problem. Table 4 shows 
hourly generation schedule, cost and emission obtained from PDED problem. It is seen from Tables 2 and 4 that the cost is 43918.3973 \$ under DED but it increases to 52045.7732 \$ under PDED and emission obtained from DED is $22349.7966 \mathrm{lb}$ but decreases to $17892.6468 \mathrm{lb}$ under PDED. Table 3 shows hourly generation schedule, cost and emission obtained from DEED problem. It can be seen that the cost is $46169.4140 \$$ which is more than $43918.3973 \$$ and less than $52045.7732 \$$, and emission is $18268.1766 \mathrm{lb}$ which is less $22349.7966 \mathrm{lb}$ and more than $17892.6468 \mathrm{lb}$. Table 5 shows that, the effectiveness of the proposed method compared with other method for DEED problem at different weighting factors. It can be seen that both fuel cost and emission less than other method reported in the literature.

Table 2. Hourly power schedule obtained from DED $\left(w_{1}=1, w_{2}=0\right)$

\begin{tabular}{ccccccc}
\hline $\mathrm{H}$ & $\mathrm{P}_{1}$ & $\mathrm{P}_{2}$ & $\mathrm{P}_{3}$ & $\mathrm{P}_{4}$ & $\mathrm{P}_{5}$ & Loss \\
\hline 1 & 25.8613 & 98.5398 & 30.0000 & 209.8159 & 50.0000 & 4.2170 \\
2 & 51.2610 & 98.5398 & 30.0000 & 209.8158 & 50.0000 & 4.6166 \\
3 & 75.0000 & 22.9669 & 32.4448 & 209.8383 & 139.9502 & 5.2002 \\
4 & 65.1616 & 98.5396 & 112.6735 & 209.8158 & 50.0000 & 6.1905 \\
5 & 75.0000 & 116.5526 & 113.4974 & 209.8265 & 50.0014 & 6.8777 \\
6 & 50.2043 & 98.5422 & 112.6735 & 124.9079 & 229.5196 & 7.8474 \\
7 & 73.5449 & 98.5227 & 112.6735 & 209.8158 & 139.7598 & 8.3167 \\
8 & 41.7130 & 69.3949 & 112.6739 & 209.8158 & 229.5196 & 9.1172 \\
9 & 38.0068 & 98.5398 & 124.2545 & 209.8158 & 229.5196 & 10.1365 \\
10 & 24.0453 & 98.5608 & 112.6736 & 249.9999 & 229.5196 & 10.7991 \\
11 & 18.0329 & 98.5471 & 175.0000 & 209.8158 & 229.5196 & 10.9154 \\
12 & 35.5302 & 101.6053 & 175.0000 & 209.8158 & 229.5196 & 11.4709 \\
13 & 64.0110 & 98.5398 & 112.6732 & 209.8158 & 229.5196 & 10.5595 \\
14 & 65.5803 & 20.0000 & 174.9999 & 209.8158 & 229.5196 & 9.9155 \\
15 & 12.6582 & 98.5839 & 112.6806 & 209.8158 & 229.5196 & 9.2580 \\
16 & 74.9994 & 20.0000 & 174.9997 & 87.6227 & 229.5196 & 7.1414 \\
17 & 12.9325 & 22.1982 & 175.0000 & 124.9080 & 229.5196 & 6.5582 \\
18 & 55.0792 & 98.5398 & 112.6734 & 209.8158 & 139.7598 & 7.8679 \\
19 & 39.8428 & 98.5455 & 174.9996 & 209.8158 & 139.7598 & 8.9635 \\
20 & 64.2197 & 98.3313 & 112.6725 & 209.8158 & 229.5196 & 10.5588 \\
21 & 55.3004 & 20.0000 & 175.0000 & 209.8158 & 229.5196 & 9.6358 \\
22 & 52.0075 & 98.5399 & 112.6735 & 209.8158 & 139.7598 & 7.7965 \\
23 & 56.8895 & 98.5400 & 112.6734 & 124.9079 & 139.7598 & 5.7705 \\
24 & 10.0000 & 20.0014 & 112.6728 & 40.0000 & 285.4157 & 5.0900 \\
\hline & & $\mathrm{Cost}=43918.3973 \$, \mathrm{Emission}=22349.79661 \mathrm{~b}, \mathrm{Loss}=194.8210 \mathrm{MW}$ & \\
\hline
\end{tabular}

Table 3. Hourly power schedule obtained from DEED $\left(w_{1}=w_{2}=0.5\right)$

\begin{tabular}{ccccccc}
\hline $\mathrm{H}$ & $\mathrm{P}_{1}$ & $\mathrm{P}_{2}$ & $\mathrm{P}_{3}$ & $\mathrm{P}_{4}$ & $\mathrm{P}_{5}$ & Loss \\
\hline 1 & 56.2125 & 69.7261 & 112.6735 & 124.9079 & 50.0000 & 3.5200 \\
2 & 58.5573 & 92.8684 & 112.6735 & 124.9079 & 50.0000 & 4.0071 \\
3 & 75.0000 & 76.8369 & 131.9377 & 124.9079 & 70.9978 & 4.6804 \\
4 & 74.8300 & 92.1340 & 112.6735 & 124.9079 & 131.2762 & 5.8216 \\
5 & 74.9999 & 98.1825 & 127.0057 & 124.9079 & 139.3488 & 6.4448 \\
6 & 75.0000 & 98.5349 & 155.2811 & 147.0503 & 139.7597 & 7.6259 \\
7 & 75.0000 & 98.5342 & 130.7738 & 190.3344 & 139.5529 & 8.1954 \\
8 & 75.0000 & 110.0955 & 128.4008 & 209.7840 & 139.7596 & 9.0400 \\
9 & 75.0000 & 99.7630 & 175.0000 & 210.1963 & 139.9548 & 9.9141 \\
10 & 75.0000 & 114.3818 & 174.9986 & 209.9598 & 140.0183 & 10.3584 \\
11 & 75.0000 & 118.5670 & 175.0000 & 219.9304 & 142.3734 & 10.8708 \\
12 & 75.0000 & 108.3505 & 175.0000 & 238.0187 & 155.1214 & 11.4906 \\
13 & 75.0000 & 110.0082 & 175.0000 & 210.8050 & 143.5295 & 10.3427 \\
14 & 75.0000 & 105.0828 & 171.8835 & 208.2014 & 139.7587 & 9.9263 \\
15 & 75.0000 & 98.5380 & 142.8135 & 206.8483 & 139.7569 & 8.9567 \\
16 & 74.9999 & 95.3435 & 152.9018 & 124.9079 & 138.7789 & 6.9321 \\
17 & 75.0000 & 98.5376 & 123.9906 & 127.1628 & 139.7597 & 6.4507 \\
18 & 75.0000 & 98.5398 & 174.4717 & 127.8544 & 139.7594 & 7.6253 \\
19 & 75.0000 & 98.2779 & 160.3730 & 189.5171 & 139.7086 & 8.8765 \\
20 & 75.0000 & 115.1852 & 174.6733 & 209.7439 & 139.7588 & 10.3612 \\
21 & 75.0000 & 98.5044 & 171.4495 & 204.9053 & 139.7585 & 9.6176 \\
22 & 75.0000 & 98.5376 & 113.9618 & 185.4355 & 139.7597 & 7.6946 \\
23 & 73.5532 & 97.6849 & 112.6735 & 124.9079 & 123.9483 & 5.7678 \\
24 & 74.9999 & 98.3978 & 112.6741 & 124.9079 & 56.5525 & 4.5322 \\
\hline & \multicolumn{7}{c}{ Cost $=46169.4140 \$, \mathrm{Emission}=18268.17661 \mathrm{~b}, \mathrm{Loss}=189.0527 \mathrm{MW}$} & \\
\hline
\end{tabular}


Table 4. Hourly power schedule obtained from PDED $\left(w_{1}=0, w_{2}=1\right)$

\begin{tabular}{ccccccc}
\hline $\mathrm{H}$ & $\mathrm{P}_{1}$ & $\mathrm{P}_{2}$ & $\mathrm{P}_{3}$ & $\mathrm{P}_{4}$ & $\mathrm{P}_{5}$ & Loss \\
\hline 1 & 54.6786 & 58.2356 & 116.5716 & 110.5981 & 73.3640 & 3.4480 \\
2 & 58.0672 & 62.3819 & 121.8509 & 117.9836 & 78.6018 & 3.8854 \\
3 & 63.5262 & 69.0800 & 130.2207 & 129.7505 & 87.0639 & 4.6413 \\
4 & 71.1207 & 78.4277 & 141.5527 & 145.8016 & 98.8910 & 5.7936 \\
5 & 74.9999 & 83.3154 & 147.2323 & 153.9048 & 104.9785 & 6.4309 \\
6 & 75.0000 & 91.9499 & 159.4748 & 170.2298 & 118.9950 & 7.6494 \\
7 & 75.0000 & 95.1864 & 164.1954 & 177.1523 & 122.5852 & 8.1193 \\
8 & 75.0000 & 94.8816 & 168.7868 & 190.1070 & 134.0911 & 8.8665 \\
9 & 75.0000 & 85.7558 & 174.9838 & 210.8898 & 153.2434 & 9.8728 \\
10 & 75.0000 & 98.8818 & 173.6087 & 214.1101 & 152.7137 & 10.3143 \\
11 & 75.0000 & 111.2904 & 174.9776 & 215.4427 & 154.1092 & 10.8198 \\
12 & 75.0000 & 121.9403 & 174.9968 & 219.0873 & 160.4403 & 1.4647 \\
13 & 75.0000 & 118.6921 & 165.7814 & 213.3878 & 141.5334 & 10.3947 \\
14 & 75.0000 & 107.6590 & 173.7776 & 200.5836 & 142.8876 & 9.9078 \\
15 & 75.0000 & 111.5516 & 162.4142 & 182.0796 & 131.8580 & 8.9033 \\
16 & 75.0000 & 87.9110 & 151.9306 & 161.2752 & 110.8391 & 6.9559 \\
17 & 75.0000 & 83.2731 & 147.2534 & 153.9011 & 105.0031 & 6.4308 \\
18 & 75.0000 & 94.9973 & 157.1994 & 171.8454 & 116.6214 & 7.6636 \\
19 & 75.0000 & 96.9959 & 171.2959 & 186.1810 & 133.3893 & 8.8622 \\
20 & 75.0000 & 120.3442 & 174.8855 & 191.8065 & 152.2863 & 10.3226 \\
21 & 75.0000 & 112.1216 & 173.5918 & 191.3485 & 137.5616 & 9.6234 \\
22 & 75.0000 & 93.8975 & 156.7095 & 168.6037 & 118.3678 & 7.5785 \\
23 & 70.7035 & 77.9152 & 140.9381 & 144.9311 & 98.2394 & 5.7274 \\
24 & 61.8833 & 67.0622 & 127.7208 & 126.2268 & 84.5143 & 4.4073 \\
\hline \multicolumn{7}{c}{} \\
\hline
\end{tabular}

Table 5. Comparison results for 5-unit system

\begin{tabular}{llll}
\hline Weight & Method & Cost $(\$)$ & Emission $(\mathrm{lb})$ \\
\hline$w_{1}=1 ; w_{2}=0$ & PSO [24] & 47852 & 22405 \\
& DE-SQP [25] & 45590 & 23567 \\
& ALO & 43918.3973 & 22349.7966 \\
$w_{1}=w_{2}=0.5$ & PSO [24] & 50893 & 20163 \\
& DE-SQP [25] & 46625 & 20527 \\
$w_{1}=0 ; w_{2}=1$ & ALO & 46169.4140 & 18268.1766 \\
& PSO [24] & 53086 & 19094 \\
& DE-SQP [25] & 52611 & 18955 \\
& ALO & 52045.7732 & 17892.6468 \\
\hline
\end{tabular}

\section{CONCLUSION}

In this paper, Ant Lion Optimization (ALO) has been successfully applied for solving the DEED problem. The effectiveness of this algorithm is demonstrated on 5-unit generation system. The results obtained from the test systems have indicated that the proposed technique has a much better performance than other optimization methods reported in the literature. The main advantage of proposed algorithm is a good ability for finding the solution. From the results obtained it can be concluded that the proposed algorithm is a competitive technique for solving complex non-smooth optimization problems in power systemoperation.

\section{APPENDIX}

Table A-1. Data for the 5-unit system

\begin{tabular}{lccccc}
\hline Quantities & Unit 1 & Unit 2 & Unit 3 & Unit 4 & Unit 5 \\
\hline$a_{i}\left(\$ /(\mathrm{MW})^{2} \mathrm{~h}\right)$ & 0.0080 & 0.0030 & 0.0012 & 0.0010 & 0.0015 \\
$b_{i}(\$ / \mathrm{MWh})$ & 2.0 & 1.8 & 2.1 & 2.0 & 1.8 \\
$c_{i}(\$ / \mathrm{h})$ & 25 & 60 & 100 & 120 & 40 \\
$e_{i}(\$ / \mathrm{h})$ & 100 & 140 & 160 & 180 & 200 \\
$f_{i}(\mathrm{rad} / \mathrm{MW})$ & 0.042 & 0.040 & 0.038 & 0.037 & 0.035 \\
$\alpha_{i}\left(\mathrm{lb} / \mathrm{MW}{ }^{2} \mathrm{~h}\right)$ & 0.0180 & 0.0150 & 0.0105 & 0.0080 & 0.0120 \\
$\beta_{i}(\mathrm{lb} / \mathrm{MWh})$ & -0.805 & -0.555 & -1.355 & -0.600 & -0.555 \\
$\gamma_{i}(\mathrm{lb} / \mathrm{h})$ & 80 & 50 & 60 & 45 & 30 \\
$\eta_{i}(\mathrm{lb} / \mathrm{h})$ & 0.6550 & 0.5773 & 0.4968 & 0.4860 & 0.5035 \\
$\delta_{i}(1 / \mathrm{MW})$ & 0.02846 & 0.02446 & 0.02270 & 0.01948 & 0.02075 \\
$P_{i, \min }(\mathrm{MW})$ & 10 & 20 & 30 & 40 & 50 \\
$P_{i, \max }(\mathrm{MW})$ & 75 & 125 & 175 & 250 & 300 \\
$U R_{i}(\mathrm{MW} / \mathrm{h})$ & 30 & 30 & 40 & 50 & 50 \\
$D R_{i}(\mathrm{MW} / \mathrm{h})$ & 30 & 30 & 40 & 50 & 50 \\
$\mathrm{POZ} \mathrm{s}-1$ & {$[2530]$} & {$[4550]$} & {$[6070]$} & {$[95110]$} & {$[80100]$} \\
$\mathrm{POZ}_{\mathrm{s}-2}$ & {$[5560]$} & {$[8090]$} & {$[125140]$} & {$[160180]$} & {$[175200]$} \\
\hline
\end{tabular}

Bulletin of Electr Eng \& Inf, Vol. 9, No. 1, February $2020: 12-20$ 
Table A-2. B-los s coefficients (5-unit system)

\begin{tabular}{|c|c|c|}
\hline$B=$ & $\left.\begin{array}{lllll}0.000049 & 0.000014 & 0.000015 & 0.000015 & 0.000020 \\
0.000014 & 0.000045 & 0.000016 & 0.0000200 .000018 \\
0.000015 & 0.000016 & 0.000039 & 0.0000100 .000012 \\
0.000015 & 0.000020 & 0.000010 & 0.0000400 .000014 \\
0.000020 & 0.000018 & 0.000012 & 0.0000140 .000035\end{array}\right]$ & perMW \\
\hline
\end{tabular}

Table A-3. Load demand for 24 hours (5-unit system)

\begin{tabular}{cccccccc}
\hline $\begin{array}{c}\text { Time } \\
(\mathrm{h})\end{array}$ & $\begin{array}{c}\text { Load } \\
(\mathrm{MW})\end{array}$ & $\begin{array}{c}\text { Time } \\
(\mathrm{h})\end{array}$ & $\begin{array}{c}\text { Load } \\
(\mathrm{MW})\end{array}$ & $\begin{array}{c}\text { Time } \\
(\mathrm{h})\end{array}$ & $\begin{array}{c}\text { Load } \\
(\mathrm{MW})\end{array}$ & $\begin{array}{c}\text { Time } \\
(\mathrm{h})\end{array}$ & $\begin{array}{c}\text { Load } \\
(\mathrm{MW})\end{array}$ \\
\hline 1 & 410 & 7 & 626 & 13 & 704 & 19 & 654 \\
2 & 435 & 8 & 654 & 14 & 690 & 20 & 704 \\
3 & 475 & 9 & 690 & 15 & 654 & 21 & 680 \\
4 & 530 & 10 & 704 & 16 & 580 & 22 & 605 \\
5 & 558 & 11 & 720 & 17 & 558 & 23 & 527 \\
6 & 608 & 12 & 740 & 18 & 608 & 24 & 463 \\
\hline
\end{tabular}

\section{REFERENCES}

[1] X. S. Han, H. B. Gooi and D. S. Kirschen, "Dynamic economic dispatch: feasible and optimal solutions," in IEEE Transactions on Power Systems, vol. 16, no. 1, pp. 22-28, Feb 2001.

[2] X. Xia and A. M. Elaiw, "Optimal dynamic economic dispatch of generation: a review," Elect. Power Syst. Res., vol. 80, no. 8, pp. 975-986, 2010

[3] X. Yuan, A. Su, Y. Yuan, H. Nie and L. Wang, "An improved PSO for dy namic load dispatch of generators with valve-point effects," Energy, vol. 34, pp.67-74, 2009.

[4] J. S. Alsumait, M. Qasem, J. K. Sykulski and A. K. Al-Othman, "An improved pattern search based algorithm to solve the dynamic economic dispatch problem with valve-point effect," Energy Conversion and Management, vol. 51, pp. 2062-2067, 2010.

[5] S. Sivasubramani and K. S. Swarup, "Hybrid SOA-SQP algorithm for dynamic economic dispatch with valve-point effects," Energy, vol. 35, pp. 5031-5036, 2010.

[6] T. A. A. Victoire and A. E. Jeyakumar, "Deterministically guided PSO for dynamic dispatch considering valve-point-effect," Elect. Power Syst. Res., vol. 73, no. 3, pp. 313-322, 2005.

[7] Zwe-Lee Gaing, "Constrained dynamic economic dispatch solution using particle swarm optimization," IEEE Power Engineering Society General Meeting, 2004., Denver, CO, vol. 1, pp. 153-158, 2004.

[8] M. Basu, "Artificial immune system for dynamic economic dispatch," International Journal of Electrical Power \& Energy Systems, vol. 33, no. 1, pp. 131-136, 2011.

[9] F. Benhamida et al., "a solution to dynamic economic dispatch with prohibited zones using a hopfield neural network," $7^{\text {th }}$ International Conference on Electrical and Electronic Engineering, Bursa, Turkey, pp. 423-427, 1-4 December 2011.

[10] M. A. Abido, "Environmental/economic power dispatch using multiobjective evolutionary algorithms," in IEEE Transactions on Power Systems, vol. 18, no. 4, pp. 1529-1537, Nov 2003.

[11] M. Basu, "Evolutionary Programming-based goal-attainment method for economic emission load dispatch with non-smooth fuel cost and emission level functions," Journal of The Institution of Engineers (India), vol. 86, pp. 95-99, 2005.

[12] U. Güvenç, "Combined economic emission dispatch solution using genetic algorithm based on similarity crossover," Sci. Res. Essay, vol. 5, no. 17, pp.2451-2456, 2010.

[13] Y. Sonmez, "Multi-objective environmental/economic dispatch solution with penalty factor using artificial bee colony algorithm," Sci. Res. Essay, vol. 6, no. 13, pp. 2824-2831, 2011.

[14] K. Vaisakh, P. Praveena and K. N. Sujatha, "Solution of dynamic economic emission dispatch problem by hybrid bacterial foraging algorithm," International Journal of Computer Science and Electronics Engineering, vol. 2, no. 1 , pp. 58-64, 2014.

[15] M. A. Abido, "A novel multiobjective evolutionary algorithm for environmental/economic power dispatch," Electric Power Systems Research, vol. 65, pp. 71-81, 2003.

[16] Hong-Tzer Yang, Pai-Chuan Yang and Ching-Lien Huang, "Evolutionary programming based economic dispatch for units with non-smooth fuel cost functions," in IEEE Transactions on Power Systems, vol. 11, no. 1, pp. 112-118, Feb 1996.

[17] Zwe-Lee Gaing, "Particle swarm optimization to solving the economic dispatch considering the generator constraints," in IEEE Transactions on Power Systems, vol. 18, no. 3, pp. 1187-1195, Aug 2003.

[18] S. Duman, U. Güvenç and N. Yorukeren, "Gravitational search algorithm for economic dispatch with valve-point effects," International Review of Electrical Engineering, vol. 5, no. 6, pp. 2890-2895, 2010. 
[19] R. Balamuruga and S. Subramanian, "An improved differential evolution based dynamic economic dispatch with nonsmooth fuel cost function," Journal of Electrical Systems, vol. 3, no. 3, pp. 151-161, 2007.

[20] B. Mohammadi-ivatloo, A. Rabiee and M. Ehsan, "Time vary ing acceleration coefficients ip so for solving dy namic economic dispatch with non-smooth cost function," Energy Conversion and Management, vol. 56, pp. 175-183, 2012.

[21] B. Mohammadi-ivatloo, A. Rabiee, A. Soroudi and M. Ehsan, "Imperialist competitive algorithm for solving nonconvex dy namic economic power dispatch,” Energy, vol. 44, pp. 228-240, 2012.

[22] Rajkumari Batham, Kalpana Jain and Manjaree Pandit, "Improved particle swarm optimization approach for nonconvex static and dynamic economic power dispatch," International Journal of Engineering, Science and Technology, vol. 3, no. 4, pp. 130-146, 2011.

[23] S. Mirjalili, "The ant lion optimizer,"Advanced in Engineering Software, vol. 83, pp. 80-98, 2015.

[24] M. Basu, "Particle swarm optimization based goal-attainment method for dynamic economic emission dispatch," Electric Power Components and Systems, vol. 34, pp. 1015-1025, 2006.

[25] A. M. Shehata and A. M. Elaiw, "Hybrid DE-SQP for solving dy namic economic emission dispatch with prohibited operating zones", International Journal of Scientific \& Engineering Research, vol. 6, no. 10, pp. 1136-1141, October 2015. 